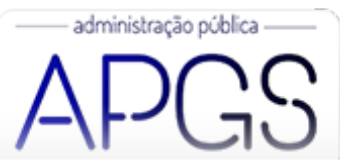

Administração Pública e Gestão Social ISSN: 2175-5787

apgs@ufv.br

Universidade Federal de Viçosa

Brasil

\title{
Elementos Marcantes da Prestação de Contas Voluntária das 100 Melhores ONGS do Brasil
}

Cavalari Sales, Jaqueline; Portulhak, Henrique; Pacheco, Vicente

Elementos Marcantes da Prestação de Contas Voluntária das 100 Melhores ONGS do Brasil

Administração Pública e Gestão Social, vol. 13, núm. 2, 2021

Universidade Federal de Viçosa, Brasil

Disponible en: http://www.redalyc.org/articulo.oa?id=351566014006

\section{(c) $(1) \Theta \theta$}

Esta obra está bajo una Licencia Creative Commons Atribución-NoComercial-SinDerivar 3.0 Internacional. 


\section{Elementos Marcantes da Prestação de Contas Voluntária das 100 Melhores ONGS do Brasil}

\section{Major Elements of Accountability of Brazil's 100 Best NGOS}

Elementos Destacados de la Rendición de Cuentas Voluntaria de las 100 Mejores ONGs En Brasil

Jaqueline Cavalari Sales

Doutoranda em Contabilidade pela Universidade Federal

Redalyc: http://www.redalyc.org/articulo.oa?

do Paraná; Economista da Universidade Federal do

Paraná, Brasil

sales@ufpr.br

Henrique Portulhak

Universidade Federal do Paraná, Brasil

henrique.portulhak@ufpr.br

Vicente Pacheco

Universidade Federal do Paraná, Brasil

vpacheco@ufpr.br

\section{Resumo:}

Objetivo da pesquisa: Identificar os elementos presentes na prestação de contas voluntária das 100 melhores organizações não governamentais (ONGs) do Brasil de 2018 de acordo com o Instituto Doar e Rede Filantropia.

Enquadramento teórico: Com base na Teoria da Divulgação, entende-se que a obrigação das ONGs com a accountability deve ir além das exigências legais de entes públicos para justificar a confiança dos doadores e manter a seu favor a opinião pública.

Metodologia: A partir de consulta aos websites das 100 organizações estudadas, aplicou-se um checklist composto por 73 itens, baseado em Gandía (2009) e Gordon, Khumawala, Kraut e Neely (2010), considerando as cinco dimensões de eficácia dadas por Gordon et al. (2010): completude, acessibilidade, transparência, divulgação total e relevância. Fazendo uso de estatística descritiva, a análise considerou o porte das instituições, com ordenação por quartis pela receita total anual.

Resultados: As ONGs utilizam seus websites principalmente para fornecer informaçóes gerais e para promover suas ações (relevância), evidenciando menor participação das demais dimensões, achado coerente com estudos anteriores. Também em consonância à literatura, as ONGs de maior porte apresentaram maior accountability, excetuando-se a dimensão transparência.

Originalidade: Preenche-se uma lacuna quanto à identificação do nível de atendimento de um rol mais amplo de práticas de prestação de contas recomendadas para ONGs, visto que grande parte dos estudos semelhantes se limitou a avaliar a relevância de suas demonstrações financeiras.

Contribuições teóricas e práticas: Contribui no aspecto teórico ao identificar que ONGs de referência atribuem maior importância à dimensão "relevância" na prestação de contas e ao identificaruma relação entre porte da ONG e nível de divulgação para a maioria das dimensões analisadas. Contribui no aspecto prático para que ONGs tenham subsídios para melhorar sua prestação de contas com base em instituições de referência, aumentando a confiança de stakeholders e contribuindo para sua sustentabilidade financeira.

Palavras-Chave: Prestação de Contas Voluntária, Teoria da Divulgação, ONGs.

\section{Abstract:}

Objective: Identify the elements present in the accountability of Brazil's 100 best non-governmental organizations of 2018 according to the Instituto Doar and Rede Filantropia.

Theoretical framework: Based on Disclosure Theory, it is understood that the obligation of non-governmental organizations with accountability must go beyond the legal requirements of public entities to justify donor confidence and maintain public opinion in their favor. 
Methodology: Based on the websites of the 100 organizations studied, a checklist consisting of 73 items was applied, based on Gandía (2009) and Gordon et al. (2010), considering the five dimensions of effectiveness given by Gordon et al. (2010): completeness, accessibility, transparency, full disclosure and relevance. Using descriptive statistics, the analysis considered the size of the institutions, sorted by quartiles by total annual revenue.

Results: Non-governmental organizations use their websites mainly to provide general information and to promote their actions (relevance), showing less participation of other dimensions, a finding consistent with previous studies. Also, in line with the literature, larger non-governmental organizations had greater accountability, except for the "transparency" dimension.

Originality: A gap is filled with the identification of the level of compliance with a broader list of recommended accountability practices for non-governmental organizations, since most of the similar studies only assess the relevance of their financial statements.

Theoretical and practical contributions: Contributes to the theoretical aspect by identifying that benchmark non-governmental organizations attach greater importance to the "relevance" dimension of accountability and by identifying a relationship between the size of the non-governmental organization and the level of disclosure for most of the dimensions analyzed. It contributes in a practical way to non-governmental organizations having subsidies to improve their accountability based on benchmark institutions, increasing the trust of stakeholders and contributing to their financial sustainability.

KEYWORDS: Accountability, Disclosure Theory, Non-governmental organizations.

\section{ReSUMEN:}

Objetivo de la investigación: Identificar los elementos presentes en la rendición de cuentas voluntaria de las 100 mejores organizaciones no gubernamentales de Brasil en 2018 según el Instituto Doar y Rede Filantropia.

Marco teórico: Basado en la Teoría de Divulgación, se entiende que la obligación de las organizaciones no gubernamentales con rendición de cuentas debe ir más allá de los requisitos legales de las entidades públicas para justificar la confianza de los donantes y mantener la opinión pública a su favor.

Metodología: A partir de los sitios web de las 100 organizaciones estudiadas, se aplicó un checklist de 73 ítems, basado en Gandía (2009) y Gordon et al. (2010), considerando las cinco dimensiones de efectividad dadas por Gordon et al. (2010): integridad, accesibilidad, transparencia, divulgación total y relevancia. Utilizando estadísticas descriptivas, el análisis consideró el tamaño de las instituciones, ordenadas por cuartiles por ingresos anuales totales.

Resultados: Las organizaciones no gubernamentales utilizan sus sítios web principalmente para proporcionar información general y promover sus acciones (relevancia), mostrando menor participación de las otras dimensiones, hallazgo consistente con estudios previos. También en línea con la literatura, las organizaciones no gubernamentales más grandes tenían una mayor rendición de cuentas, a excepción por la dimensión de "transparencia".

Originalidad: Existe una brecha en la identificación del nivel de cumplimiento en una lista más amplia de prácticas de rendición de cuentas recomendadas para las organizaciones no gubernamentales, ya que la mayoría de los estudios similares se limitaron a evaluar la relevancia de sus estados financieros.

Aportes teóricos y prácticos: Contribuye en el aspecto teórico identificando que organizaciones no gubernamentales de referencia otorgan mayor importancia a la dimensión de "relevancia” en la rendición de cuentas e identificando una relación entre el tamaño de la organización no gubernamental y el nivel de divulgación para la mayoría de las dimensiones analizadas. Contribuye de manera práctica a que las organizaciones no gubernamentales tengan subsidios para mejorar su rendición de cuentas en base a instituciones de referencia, aumentando la confianza de los actores y contribuyendo a su sostenibilidad financiera.

Palabras Clave: Rendición de Cuentas Voluntaria, Teoría de Divulgación, Organizaciones no gubernamentales.

\section{INTRODUÇÃO}

Desde a década de 1980 tem-se intensificado a colaboração entre governos dos mais diferentes países e organizações privadas sem fins lucrativos. A parceria se dá principalmente em função da ineficiência do governo em atender as demandas sociais (Costa, 2017; Salamon, 1998). Como resultado, o terceiro setor apresenta relevância no Brasil e no mundo, tanto no aspecto social quanto econômico (Mañas \& Medeiros, 2012; Salamon, Sokolowski, \& List, 2003).

Nos Estados Unidos, por exemplo, o terceiro setor contribuiu com cerca de US\$985 bilhões para a economia em 2015, compondo 5,4\% do produto interno bruto (PIB) do país. De 2005 a 2015, o número de organizações sem fins lucrativos americanas subiu de 1,41 milhão para 1,56 milhão, um aumento de 10,4\%. 
Essas organizações compõem uma gama diversificada de áreas de atuação: arte, saúde, educação e defesa, sindicatos, além de associações empresariais e profissionais (McKeever, 2018).

Dentro deste universo, as instituições beneficentes compõem a maior categoria, totalizando cerca de um milhão de organizações, representando por volta de dois terços de todas as organizações sem fins lucrativos registradas. Entre 2005 e 2015, a quantidade de instituições beneficentes cresceu 28,4\%, um ritmo de crescimento mais rápido do que o observado em todas as organizações sem fins lucrativos registradas. Assim, estas aumentaram sua participação relativa no setor, passando de 60\% em 2005 para 69,7\% em 2015 (McKeever, 2018).

O Terceiro Setor, naquele país, gera 11,4 milhões de postos de trabalho, empregando $10 \%$ da população. Adicionalmente, o serviço voluntário é um importante componente do setor. Estima-se que 25,1\% da população americana participou de trabalho voluntário em 2017 (McKeever, 2018). Já o voluntariado no Brasil envolveu 7,2 milhões de pessoas em 2018, o que representou 4,3\% da população com 14 anos ou mais, segundo o Instituto Brasileiro de Geografia e Estatística (IBGE) (2019).

No Brasil, em 2016, havia cerca de 527 mil entidades sem fins lucrativos, que empregavam cerca de 3,2 milhões de trabalhadores, correspondendo a 7,2\% do pessoal ocupado assalariado. O subgrupo de fundações e associações empregava cerca de 2,3 milhões de pessoas, absorvendo 5,1\% do pessoal ocupado assalariado (IBGE, 2019).

Em função dessa expressividade, as organizações não governamentais (ONGs) passaram a atuar em um ambiente cada vez mais competitivo, onde a escassez de recursos leva tanto os financiadores quanto o públicoalvo a exigirem maior transparência, eficiência e efetividade de suas operações, conduzindo a uma necessidade de profissionalização de sua gestão (Fischer, 2004). Apesar das pressões crescentes, o terceiro setor tem mostrado resiliência, mesmo havendo evidências de perda de espaço para organizações com fins lucrativos nos campos antes tradicionalmente atendidos pelas ONGs (Salamon \& Newhouse, 2019).

Nesse contexto, a transparência e a prestação de contas têm sido apontadas como condições necessárias para a sustentabilidade das ONGs. Há evidências de que doadores anteriores fazem uso de informações contábeis financeiras ao tomar uma decisão de doação (Parsons, 2007) e que há uma relação positiva entre o nível de transparência das informações disponibilizadas nos websites e o valor econômico gerado pelas ONGs para a sociedade (Oliveira \& Coelho, 2017). Os relatórios de atividades são apontados como importantes instrumentos de comunicação entre as ONGs e seus doadores e demais stakeholders (Gordon, Khumawala, Kraut, \& Neely, 2010), atendendo a uma obrigação legal e ética de prestar contas. Para Portulhak, Delay e Pacheco (2015), há uma relação positiva entre a prestação de contas realizada por entidades do terceiro setor e o comportamento do investidor social individual.

Para incentivar as ONGs a melhorarem a gestão, a transparência, a relação com doadores e a comunicação, o Instituo Doar e a Rede Filantropia promovem o prêmio "Melhores ONGs”. Em sua segunda edição, em 2018, foram selecionadas 100 organizações dentre aquelas que espontaneamente inscreveram-se no processo, que é orientado pelo atendimento dos seguintes princípios: causa e estratégia, representação e responsabilidade, gestão e planejamento, estratégia de financiamento e comunicação e prestação de contas (Guimarães \& Craveiro, 2018).

Isso posto, o objetivo geral deste estudo é identificar os elementos presentes na prestação de contas voluntária das 100 melhores ONGs do Brasil, considerando as melhores práticas dentre cinco dimensões de eficácia: completude, acessibilidade, transparência, divulgação total e relevância, dimensões essas identificadas no trabalho de Gordon, Khumawala, Kraut e Neely (2010). Assim, busca-se responder a seguinte questão de pesquisa: Quais os elementos marcantes na prestação de contas voluntária das 100 melhores ONGs do Brasil?

A relevância e oportunidade de pesquisa justificam-se pela carência de estudos sobre o terceiro setor que identifiquem e disseminem boas práticas que possam ser adotadas pelas ONGs na prestação de contas compulsória e voluntária. Cabe ressaltar que grande parte dos estudos sobre o tema até o momento têm- 
se limitado a incorporar diferentes dados contábeis e índices financeiros para mensurar a relevância da divulgação das demonstrações financeiras para os doadores no processo de prestação de contas (Cruz, 2010; Gordon \& Khumawala, 1999; Parsons, 2007; Trussel \& Parsons, 2008). Este trabalho busca, portanto, preencher esta lacuna, identificando através de um levantamento das informações divulgadas por estas ONGs em seus websites, o nível de atendimento de um amplo rol de práticas sugeridas para organizações que busquem demonstrar seu compromisso com a accountability, considerando diferentes dimensões de eficácia (completude, acessibilidade, transparência, divulgação total e relevância).

A motivação que orienta o trabalho é o pressuposto de que as ONGs agraciadas com este prêmio evidenciem em seus websites práticas de prestação de contas que possam servir de referência para as demais organizações sem fins lucrativos direcionarem suas estratégias de divulgação voluntária, o que se torna importante para que estas tenham condições de aumentar a confiança de seus stakeholders e possibilitar sustentabilidade financeira em um ambiente de crescente competição por recursos. A escolha por estas ONGs é justificada pelo pressuposto de que organizações com melhor desempenho tenham maiores incentivos para realizar divulgação voluntária (Lang \& Lundholm, 1993).

Em específico, a investigação buscou verificar a existência de diferenças entre os elementos presentes na prestação de contas de acordo com o porte das ONGs e, existindo diferenças, identificar em quais dimensões de eficácia essas diferenças são mais presentes, também em linha com o pressuposto de que haja maior nível de divulgação voluntária por organizações com maior porte (Lang \& Lundholm, 1993). O trabalho contribui com a literatura acadêmica que trata das melhores práticas no terceiro setor e de forma geral, com todo o universo de organizações não governamentais que buscam melhorar a qualidade das informações dos relatórios de prestação de contas, promover a transparência e a comunicação com seus stakeholders e, consequentemente, aumentar a captação de recursos, possibilitando dessa forma contribuições práticas e sociais.

\section{REFERENCIAL TEÓRICO-EMPÍRICO}

\subsection{Prestação de contas das ONGs}

O termo "organizações não governamentais” ou apenas ONGs, "a sigla que já virou palavra” (Landim, 1993, p. 20), frequentemente é utilizado como sinônimo ou correlato de terceiro setor. É um termo antigo, que nasceu na Organização das Nações Unidas (ONU) no pós-guerra. No Brasil, engloba associações e fundações que são fundamentais para a caracterização e conformação do terceiro setor.

Para Korten (1990 como citado em Alves, 2002), as ONGs representam quatro tipos de organizações: (I) voluntárias, orientadas pelo compromisso social; (II) contratadas de serviço público, busca resultados sociais, mas com orientação de mercado; (III) organizações populares, que representam os interesses de seus integrantes e geralmente são autossustentáveis; e (IV) as ONGs governamentais (gongos em inglês), que são criadas por governos e servem para vários objetivos de políticas públicas.

$\mathrm{Na}$ América Latina, o termo “ONG” em sua origem está associado a organizações formadas a partir de frentes sociais e embates contra a ditadura, que buscavam influenciar as políticas públicas sociais. Esse caráter militante e reivindicatório dá ao termo "ONG" uma conotação mais politizada do que no resto do mundo (Landim, 1993).

Na década de 1990, as ONGs representavam, segundo Falconer (1999, p. 3) "uma nova e grande promessa: a renovação do espaço público, o resgate da solidariedade e da cidadania, a humanização do capitalismo e, se possível, a superação da pobreza". Para o autor, essa promessa se cumpriria por meio de práticas antigas, como o voluntariado e a filantropia, mas com um foco mais empresarial. Nesta trajetória de evolução das ONGs, 
fato importante foi a criação da Associação Brasileira de ONGs (ABONG) em 1991, objetivando fomentar a interação entre as instituições sem fins lucrativos (Lima, 2016).

Fato também importante foi a regulamentação do Marco Regulatório das Organizações da Sociedade Civil (2015), alterado pela Lei n. 13.204 (2015). Este instrumento legal procura criar um ambiente normativo suficientemente capaz de acompanhar o protagonismo da sociedade civil na execução e acompanhamento das políticas públicas Foram introduzidos por essa legislação novos instrumentos de formalização de parceiras entre o poder público e as ONGs, como o Termo de Colaboração e o Termo de Fomento. No caso do primeiro instrumento, a proposição do projeto parte da Administração Pública e, no segundo instrumento, a iniciativa parte da ONG.

Independente da nomenclatura utilizada para denominar essas organizações, o fato é que as ONGs têm representado papel importante de parceria com o Estado na implementação de políticas públicas (Costa, 2017; Salamon, 1998), desempenhando as mais diversas funções, sobretudo em áreas sociais. Para execução desta tarefa, em um ambiente cada vez mais competitivo, de escassez de recursos financeiros e diante da limitação e dependência do trabalho voluntário, as ONGs precisam ter maior visibilidade em termos de eficiência e efetividade no desempenho organizacional, estarem aptas a realizar parcerias que exigem padrões de desempenho específicos e capacidade de articulação e, ainda, serem capazes de competir com o setor empresarial em termos de atratividade de profissionais qualificados (Fischer, 2004; Salamon \& Newhouse, 2019).

Nesse cenário, as ONGs precisam também qualificar sua comunicação para tentar igualar-se aos atores governamentais e empresariais, muito embora esse seja um desafio adicional diante da busca persistente por índices satisfatórios de eficiência. (Krlev \& Lund, 2020). Também no terceiro setor há evidências de que os gestores sofrem pressão e estão dispostos a gerenciar índices de resultado. Contudo, o estudo de Parsons, Pryor e Roberts (2017) relata que não há evidências que a dependência de doações constitua elemento suficiente para a manipulação contábil por parte das ONGs. Os achados sugerem que os gestores se concentram em doadores específicos e não necessariamente na dependência geral de doações. A pressão que leva à disposição de gerenciar resultados provém de doadores de programas específicos ou de financiamentos do governo, que demandam o atendimento de cláusulas contratuais pontuais e com forte monitoramento.

Quanto à comunicação, há evidências de que as atividades do terceiro setor não recebem a mesma atenção da mídia quando comparadas com o governo e o setor empresarial, o que pode ser prejudicial para as ONGs em termos políticos, financeiros e de recursos humanos. A mídia vê as atividades do terceiro setor, em geral, como atividades auxiliares e de pouca inovação, em termos de novas abordagens de demandas sociais (Krlev \& Lund, 2020).

Embora reconheçam o papel das mídias sociais (Facebook, Twitter, etc.), Krlev e Lund (2020) destacam que os jornais impressos e on-line têm influência significativa na tomada de decisão dos temas que entram na agenda de políticas públicas e sobre a visibilidade das organizações, influenciando o debate público, as decisões do voluntariado e dos doadores.

A busca por maior visibilidade pode passar pela observação dos princípios da Teoria da Divulgação, apresentada por Verrecchia (2001). A Teoria tem sido a base para diferentes estudos que buscam explicar os efeitos da divulgação voluntária no preço de mercado das ações, as razões econômicas para que determinada informação seja divulgada voluntariamente e o custo/benefício envolvido no processo de divulgação voluntária.

Para o entendimento da Teoria da Divulgação o ponto de partida é a redução da assimetria informacional. O gestor exerce a discricionariedade para eleger o que será ou não evidenciado, revelando uma tendência a divulgar com destaque as informações favoráveis e omitir, dissimular ou atrasar a divulgação de informações desfavoráveis (Verrecchia, 2001).

Contudo, tanto os eventos positivos quanto os negativos relacionados aos diferentes stakeholders devem ser igualmente divulgados pelas ONGs, com o objetivo de manter sua legitimidade e demonstrar sua 
responsabilidade com a transparência (Gordon et al., 2010). A gestão dessas organizações deve evitar ser acusada de ocultar intencionalmente informações relevantes. Perseguir uma causa nobre não é suficiente para evitar questionamentos sobre a correta aplicação dos recursos, principalmente diante de evidências de fraudes, corrupção e desvio de finalidades (Oliveira \& Coelho, 2017).

Nesse contexto da Teoria da Divulgação, deve-se considerar a existência de restrições e incentivos para a divulgação voluntária, seja a respeito de informações favoráveis ou desfavoráveis para a organização que reporta. Dentre estes fatores, podem ser elencados o desempenho da entidade, em que haveria a tendência de maior nível de divulgação por organizações com melhor desempenho, e o porte, em que haveria a tendência de maior nível de divulgação por organizações com maior porte (Lang \& Lundholm, 1993).

\subsection{Estudos anteriores}

Já no final dos anos 1990, Falconer (1999) apontava que o cenário até então desenhado pela atuação das ONGs no Brasil passava por uma rápida transformação. Para o autor, até então, grande parte das organizações havia sido fruto de um contexto político de repressão e atuava há tempos quase na clandestinidade. Inclusive, aquelas que recebiam recursos na forma de subvenções não prezavam pela transparência, ao contrário, as ONGs haviam descoberto que, para conseguir recursos, tinham que trilhar os caminhos duvidosos dos interesses clientelistas ou entendiam que sua simples existência ou validade da causa defendida justificavam as doações recebidas. Muitas dessas organizações nunca chegaram a assimilar seu caráter público (Falconer, 1999).

À medida que se desenvolveram, as ONGs, como qualquer outro tipo de organização, ganharam volume e complexidade e passaram a enfrentar problemas típicos de uma estrutura burocrática, como tensões entre flexibilidade e efetividade e accountability, este último termo entendido como o dever de ser transparente e prestar contas, não apenas em relação aos recursos financeiros, mas também quanto ao seu impacto social (Lima, 2016; Salamon, 1998).

Diferentes estudos brasileiros e estrangeiros apontam que o compromisso com a transparência e a prestação de contas (accountability) são condicionantes da legitimidade institucional e sobrevivência das organizações não governamentais (Cruz, 2010; Gordon et al., 2010; Lima, 2016; Oliveira \& Coelho, 2017; Parsons, 2007; Portulhak, Delay, \& Pacheco, 2015). A evidenciação contábil das ONGs é crucial para a transparência e, ao incorporar elementos qualitativos adequados, possibilita a avaliação do retorno social das organizações (Mário, Paula, Alves, \& Jupetibe, 2013). Evidências empíricas de amostra estudada no Brasil indicam a relevância da informação contábil para investidores sociais privados (Cruz, 2010).

Gandía (2009) investigou a relevância da divulgação voluntária na internet sobre a melhoria da transparência informacional de ONGs espanholas, analisando como as organizações usam seus websites e o efeito que os níveis de divulgação têm na captação de recursos. De forma geral, os resultados estatísticos revelaram baixos níveis de divulgação e o uso dos sites para divulgação de informações de natureza geral e com propósitos promocionais, não se constituindo em um conjunto de informações que pudesse ser considerado relevante.

$\mathrm{Na}$ realidade, de acordo com o mesmo autor, os sites das ONGs pesquisadas acabam sendo mais ornamentais do que interativos e deliberativos, priorizando informações sobre missão, visão, objetivos, impacto social de suas atividades e serviço de notícias, portanto, a principal estratégica dessas ONGs é ter presença na internet, passando uma imagem de modernidade e inovação, por vezes apenas imitando sites de outras ONGs. Da mesma forma, Gordon et al. (2010), afirma que pode haver uma tendência das ONGs em informar o mesmo que seus concorrentes mais próximos, dando maior destaque à sua relevância.

A necessidade de divulgação voluntária é confirmada por achados de pesquisa, justificando esforços adicionais de disponibilização de informações contábeis em websites orientados para doadores em potencial e que agregam informações de diferentes ONGs (Parsons, 2007). Para Banding e Mayangsari (2017), 
divulgações em suas várias formas são exigidas pelos doadores A eficiência na alocação de recursos, a estabilidade financeira da organização, a disponiblidade de informações para os doadores e a reputação da ONG podem influenciar a decisão de doação (Trussel \& Parsons, 2008). Da mesma forma, a falta de uma comunicação qualificada pode afetar o recrutamento de trabalho voluntário, a captação de recursos e o debate público (Krlev \& Lund, 2020).

A obrigação das ONGs com a accountability deve ir além das exigências legais dos diferentes entes públicos para justificar a confiança dos doadores e para manter a seu favor a opinião pública (Gordon et al., 2010). Através da avaliação dos relatórios anuais de 75 ONGs, esses autores exemplificaram boas práticas, considerando cinco dimensões de eficácia: completude, acessibilidade, transparência, divulgação total e relevância:

- Completude: Considera se foram divulgadas demonstrações financeiras obrigatórias e voluntárias auditadas ou revisadas. Completude não está relacionada ao número de páginas do relatório anual, mas à supervisão técnica e legal de seu conteúdo, i.e., parecer técnico.

- Acessibilidade: Por mais completas que sejam as informações, elas não terão validade se o usuário não tiver fácil acesso e tempestividade na informação. Os relatórios devem estar prontamente disponíveis.

- Transparência: Clareza e inteligibilidade da apresentação são essenciais. Deve permitir ao usuário "ver através" dos números e entender as atividades da ONG. Transações incomuns ou pouco frequentes constantes das demonstrações financeiras devem ser explicadas. As notas explicativas devem contribuir com a transparência.

- Divulgação total: As organizações devem achar o equilíbrio entre a inclusão de detalhes suficientes para divulgar informações que façam a diferença para os usuários e agregação suficiente para tornar a informação compreensível e evitar sobrecarga de informação. Divulgações voluntárias importantes incluem transações com partes relacionadas, práticas de governança, políticas relacionadas ao doador e relatos de eventuais conflitos de interesse, evitando o fator surpresa.

- Relevância: Não é simples medir o desempenho financeiro de uma ONG. Diferentemente de uma empresa, a diferença entre receitas e despesas não é um parâmetro ideal, embora sirva para sinalizar a sobrevivência em longo prazo da organização. A contabilidade financeira é incapaz de mostrar por si só se a missão da ONG está sendo cumprida. Informações sobre a realização dos objetivos da ONG, dadas sua missão e sua visão, são as mais relevantes para os stakeholders. As realizações devem vislumbrar um período de três a cinco anos, juntamente com a discussão de quaisquer tendências.

Uma boa reputação é valiosa para uma ONG, mas é frágil. Certamente, a adoção de boas práticas na prestação de contas irá colaborar para perpetuidade da organização, reduzindo a assimetria informacional e auxiliando a tomada de decisão do investidor social sobre a ONG que irá financiar (Gordon et al., 2010). Há indícios de que vários fatores influenciam a motivação do investidor social em contribuir com uma ou outra organização, dentre eles a preferência pela causa, a religião, a renda e o altruísmo. Porém, decidida a causa a ser apoiada e o valor da doação, a prestação de contas pode influenciar na decisão da organização a ser financiada (Cruz, 2010; Ebrahim, 2003; Gordon \& Khumawala, 1999).

Cabe notar que, em relação ao setor empresarial, as ONGs apresentam dificuldades e complexidades particulares na medição de seu desempenho, muito em função da intangibilidade de várias de suas ações sociais. No atual ambiente, dinâmico e turbulento, essas organizações enfrentam desafios adicionais como a instabilidade no financiamento, mudanças no âmbito político, dificuldades em atrair recursos humanos qualificados e dificuldades de acesso às modernas tecnologias de informação (Lee \& Nowell, 2015). 


\section{METODOLOGIA}

A presente investigação é tipificada como descritiva, documental e quantitativa (Sampieri, Collado, \& Lucio, 2006). Empregou análise estatística descritiva e a categorização por porte deu-se por ordenação por quartis (Langford, 2006), conforme o porte das ONGs, usando como critério de agrupamento a receita total anual. Optou-se pela receita total anual como critério de definição de porte das ONGs em função da disponibilidade desses números e considerando a ausência de informações para todas as ONGs sobre valores do ativo total ou número de funcionários, que também poderiam servir de base para a realização de agrupamentos por porte.

A população estudada é composta pelas 100 ONGs selecionadas pelo processo realizado pelo Instituto Doar e Rede Filantropia e constantes do Guia 100 Melhores ONGs de 2018 (Guimarães \& Craveiro, 2018).

O instrumento de coleta de dados (checklist) foi elaborado com base nos estudos de Gordon et al. (2010) e Gandía (2009) e é composto por 73 itens de resposta dicotômica (sim/não), elencados nas tabelas ao longo da análise de dados. Seu preenchimento se deu com base em informações divulgadas pelas ONGs em seus websites, no período de 15 a 31 de maio de 2019. A escolha dos websites das ONGs como fonte prioritária para a coleta de dados se deu pela questão da acessibilidade à informação e pela importância da internet como canal de comunicação entre as ONGs e seus diferentes stakeholders, fomentando uma relação de confiança, o que pode afetar, inclusive, o volume de captação de recursos (Gandía, 2009).

Os itens avaliados têm relação com critérios que permitem aferir as condições de completude, acessibilidade, transparência, divulgação total e relevância das informações divulgadas nos sites das organizações. A escolha dessas dimensões de eficácia é justificada com base na literatura acadêmica, pois entende-se que tais dimensões influenciam e são influenciadas pelos atuais desafios enfrentados pelas ONGs (Lee \& Nowell, 2015). Ademais, essas condições permitem avaliar a transparência, reputação e responsabilidade social das ONGs enquanto fatores condicionantes de sua sustentabilidade (Banding \& Mayangsari, 2017; Gandía, 2009; Mário et al., 2013; Parsons, 2007; Trussel \& Parsons, 2008).

Para atendimento do objetivo geral da pesquisa, partiu-se do pressuposto que as ONGs apresentariam baixo nível de divulgação de informações para prestação de contas por meio de seus websites, sendo proeminente, de forma positiva, a divulgação de informações de natureza geral relacionadas à missão, visão, objetivos e área de atuação que, entre outros itens, constituem a dimensão de relevância, tendo como base os resultados do estudo de Gandía (2009).

Já para o objetivo específico da investigação, partiu-se da hipótese de que as ONGs de maior porte apresentariam maior atendimento às cinco dimensões de eficácia, tomando como base os argumentos indicados por Salamon (1998) sobre aumento de volume e complexidade e consequente aumento de pressão por maior accountability. Também se acrescenta para formulação dessa hipótese o fato de que, como o processo de divulgação resulta em custos de preparação, organizações de maior porte possuam maiores condições de suportar tais custos (Lang \& Lundholm, 1993).

Como a análise de dados englobou toda a população de ONGs contempladas pelo prêmio de Melhores ONGs do Brasil, não foi necessária a realização de testes estatísticos por amostragem. Dessa forma, a análise dos dados para verificação desta hipótese se deu pela observação direta das frequências e respectivos percentuais de atendimento dos itens avaliados para cada dimensão entre os quartis.

\section{RESULTADOS E ANÁLISES}

A partir da consulta aos websites das 100 organizações que receberam o prêmio de Melhores ONGs de 2018 e consequente tabulação dos dados, foram identificados elementos descritivos, as frequências de respostas afirmativas e negativas para as cinco dimensões de eficácia, bem como os resultados em termos de média, considerando a ordenação por quartis. A Tabela 1 apresenta informações descritivas a respeito das ONGs pesquisadas. 
Tabela 1: Estatística descritiva das 100 Melhores ONGs do Brasil, 2018

\begin{tabular}{|c|c|c|c|c|}
\hline \multirow{2}{*}{ Quartil } & \multicolumn{2}{|c|}{$\begin{array}{l}\text { Receita } \\
\text { Total (R } \$ \text { mil) }\end{array}$} & \multicolumn{2}{|c|}{ Fundação } \\
\hline & Minimo & Máximo & $\begin{array}{c}\text { Anterior } \\
\text { a } 1995\end{array}$ & $\begin{array}{r}\text { Posterior } \\
\text { ou } 1995\end{array}$ \\
\hline 1 & 24 & 2.485 & $24 \%$ & $76 \%$ \\
\hline 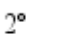 & 2.843 & 16.781 & $54 \%$ & $46 \%$ \\
\hline $3^{\circ}$ & 21.031 & 958.541 & $44 \%$ & $56 \%$ \\
\hline Quartil & $\begin{array}{l}\text { Atuação } \\
\text { al }\end{array}$ & Nacion & \multicolumn{2}{|c|}{$\begin{array}{l}\text { Informa } \\
\text { Qualificação do } \\
\text { Principal Gestor }\end{array}$} \\
\hline & $\operatorname{Sim}$ & Não & $\operatorname{Sim}$ & Não \\
\hline $1^{\circ}$ & $16 \%$ & $84 \%$ & $28 \%$ & $72 \%$ \\
\hline $2^{\circ}$ & $20 \%$ & $80 \%$ & $22 \%$ & $78 \%$ \\
\hline $3^{\circ}$ & $20 \%$ & $80 \%$ & $12 \%$ & $88 \%$ \\
\hline
\end{tabular}

$\mathrm{Na}$ Tabela 1 é possível verificar que houve um aumento no número de ONGs fundadas a partir de 1995, se considerado o $1^{\circ}$ e $3^{\circ}$ quartis, definidos com base na receita total anual. Predominantemente, observa-se que as ONGs pesquisadas têm atuação local e regional, sendo que 19 delas informam que atuam a nível nacional. Há uma concentração de ONGs nas regiões Sudeste e Sul, corroborando com os estudos de Costa (2017).

Adicionalmente, notou-se que há uma diversidade nas áreas de atuação. Essas organizações trabalham com apoio ao empreendedorismo, direitos humanos, formação de lideranças sociais, conservação da biodiversidade, educação, saúde e advocacy, com a finalidade de influenciar na formulação e implementação de políticas públicas. Essa abrangência de áreas de atuação demonstra que as ONGs na América Latina têm um caráter mais politizado do que no restante do mundo (Landim, 1993).

Frente a um ambiente cada vez mais competitivo, dada a escassez de recursos e dificuldades inerentes à limitação e dependência do trabalho voluntário, as ONGs precisam de uma gestão profissionalizada (Fischer, 2004). Contudo, apenas com base nas informações disponibilizadas on-line não foi possível tecer comentários acerca da qualificação acadêmica e profissional de suas equipes gestoras, uma vez que poucas das 100 ONGs informam dados a esse respeito, como também evidenciado na Tabela 1.

No que tange à caracterização das ONGs em termos de tamanho, foi utilizado como critério o valor da receita total anual, dividindo o conjunto de valores ordenados em quartis, como mencionado na metodologia e indicado na Tabela 1 . Dentre as ONGs que compóem o $1^{\circ}$ quartil, a receita varia de $\mathrm{R} \$ 24$ mil a $\mathrm{R} \$ 2,5$ milhões. No $2^{\circ}$ quartil a receita atinge cerca de $\mathrm{R} \$ 17$ milhões. Já no $3^{\circ}$ quartil a receita chega perto de $\mathrm{R}$ \$1 bilhão, mostrando que há uma grande dispersão nestes dados. São cinco as ONGs que possuem receita acima de $\mathrm{R} \$ 300$ milhões e destas apenas uma não é ligada a grandes complexos de atendimento à saúde. Os resultados da verificação da dimensão Completude são detalhados na Tabela 2. 
Tabela 2: Avaliação da Dimensão Completude das 100 Melhores ONGs do Brasil, 2018

\begin{tabular}{|c|c|c|}
\hline o Completude & $\begin{array}{l}\text { Total } \\
\text { Sim }\end{array}$ & Näo \\
\hline $\begin{array}{l}\text { Informa sobre processos } \\
\text { de qualidade } \\
\text { implementados pela } \\
\text { organizaçäo }\end{array}$ & 26 & 74 \\
\hline $\begin{array}{l}\text { Informa sobre o total de } \\
\text { pessoas contratadas }\end{array}$ & 27 & 73 \\
\hline $\begin{array}{l}\text { Informa sobre o número } \\
\text { total de voluntários }\end{array}$ & 4 & 76 \\
\hline $\begin{array}{l}\text { Informa sobre o } \\
\text { enquadramento legal e } \\
\text { tipo de contratos de } \\
\text { trabalho do pessoal }\end{array}$ & 9 & 91 \\
\hline $\begin{array}{l}\text { Informa sobre cursos de } \\
\text { treinamento realizados } \\
\text { pelo pessoal da } \\
\text { organizaçäo }\end{array}$ & 21 & 79 \\
\hline $\begin{array}{l}\text { Informa nomes e breve } \\
\text { histórico dos gestores }\end{array}$ & 18 & 82 \\
\hline $\begin{array}{l}\text { Disponibiliza estatutos, } \\
\text { regulamentos ou regimes } \\
\text { internos de operação }\end{array}$ & 86 & 14 \\
\hline $\begin{array}{l}\text { Divulga periodicamente } \\
\text { atas de reunioes }\end{array}$ & 1 & 99 \\
\hline $\begin{array}{l}\text { Informa sobre os } \\
\text { procedimentos para } \\
\text { eleger e remover gestores }\end{array}$ & 1 & 99 \\
\hline $\begin{array}{l}\text { Informa sobre a politica } \\
\text { de contratação e } \\
\text { remuneração de pessoal }\end{array}$ & 0 & 91 \\
\hline $\begin{array}{l}\text { Informa Orçamento } \\
\text { previsto/projetado } \\
\text { exercícios futuros }\end{array}$ & 0 & 100 \\
\hline $\begin{array}{l}\text { Oferece resumos de } \\
\text { dados financeiros }\end{array}$ & 31 & 69 \\
\hline $\begin{array}{l}\text { Säo inclúdos slides e } \\
\text { gráficos como suporte } \\
\text { para a apresentação de } \\
\text { dados financeiros }\end{array}$ & 22 & 78 \\
\hline Está disponivel o & & \\
\hline $\begin{array}{l}\text { Relatório Anual do } \\
\text { exercício } 2018\end{array}$ & 39 & 61 \\
\hline $\begin{array}{l}\text { Hả Relatórios Anuais de } \\
\text { anos anteriores (minimo } \\
\text { de } 2 \text { anos) }\end{array}$ & 73 & 27 \\
\hline $\begin{array}{l}\text { Está disponivel o Balanço } \\
\text { do exercício } 2018\end{array}$ & 40 & 60 \\
\hline $\begin{array}{l}\text { Há Balanços de anos } \\
\text { anteriores (mínimo de } 2 \\
\text { anos) }\end{array}$ & 74 & 26 \\
\hline $\begin{array}{l}\text { Há Demonstração do } \\
\text { resultado e das despesas } \\
\text { do último exercício fiscal }\end{array}$ & 41 & 59 \\
\hline $\begin{array}{l}\text { Há Demonstração do } \\
\text { resultado e das despesas } \\
\text { de anos anteriores } \\
\text { (mínimo de } 2 \text { anos) }\end{array}$ & 73 & 27 \\
\hline $\begin{array}{l}\text { Está disponivel o } \\
\text { relatório de auditoria do } \\
\text { exercício } 2018\end{array}$ & 33 & 67 \\
\hline $\begin{array}{l}\text { Há relatório de auditoria } \\
\text { de anos anteriores } \\
\text { (minimo de } 2 \text { anos) }\end{array}$ & 58 & 42 \\
\hline $\begin{array}{l}\text { Fornece as regras } \\
\text { contábeis usadas }\end{array}$ & 61 & 39 \\
\hline $\begin{array}{l}\text { Dimensão Completude } \\
\text { por Quartil }\end{array}$ & Sim & Näo \\
\hline $1^{\circ}$ Quartil & $27 \%$ & $73 \%$ \\
\hline $2^{\circ}$ Quartil & $37 \%$ & $63 \%$ \\
\hline $3^{\circ}$ Quartil & $40 \%$ & $60 \%$ \\
\hline
\end{tabular}


$\mathrm{Na}$ dimensão Completude foram avaliados itens relacionados à divulgação on-line das demonstrações contábeis como balanço patrimonial, demonstração do resultado, demonstração dos fluxos de caixa, notas explicativas, relatório de auditoria e relatório de atividades, referente ao exercício de 2018 e no mínimo dois exercícios anteriores, bem como a existência de campo para consulta de documentos relativos à constituição da organização, além de controles de qualidade e políticas de recursos humanos.

A Tabela 2 mostra que a maioria das ONGs pouco informa sobre a estrutura e funcionamento administrativo da organização, não permitindo aos stakeholders uma avaliação mais completa sobre a governança e os desafios organizacionais. São poucas as ONGs que apresentam as informações financeiras também em formas gráficas ou relatórios resumidos, o que tornaria mais completo e visualmente interessante esse tipo de conteúdo. No estudo de Gandía (2009), mais de 50\% das ONGs disponibilizavam as informações financeiras também nestes formatos. Gordon et al. (2010) evidenciaram que quatro de 51 ONGs não apresentavam nenhuma demonstração contábil, mas incluíram algum tipo de gráfico para tratar das receitas e despesas.

Cabe notar que algumas das ONGs pesquisadas que optaram por fazer a apresentação na forma resumida ou gráfica deixaram de disponibilizar os relatórios financeiros em sua forma original, dificultando o trabalho de usuários externos interessados em fazer uma análise econômico-financeira mais aprofundada. Gordon et al. (2010) apontam que é recomendável a inclusão no relatório anual das demonstrações financeiras completas e auditadas, prática adotada por $28 \%$ da amostra estudada pelos autores. No presente estudo, $33 \%$ da amostra apresentou o último relatório de auditoria.

Os resultados da dimensão Completude de forma geral, mostram que em média menos da metade dessas 100 organizações atendem a esse critério e que os melhores resultados são das ONGs maiores, do $3^{\circ}$ quartil, corroborando com os resultados de Gandía (2009), que evidenciaram que há pouca informação sobre o ambiente organizacional, implementação de processos de qualidade ou políticas de recrutamento de pessoal nos sites das ONGs espanholas. A disponibilidade dos balanços, relatórios de auditoria e informações sobre número de funcionários foram os itens com maior discrepância entre o $1^{\circ} \mathrm{e} 3^{\circ}$ quartis.

A Tabela 3 apresenta os resultados detalhados da verificação da dimensão Acessibilidade. Como demonstrado na tabela, as ONGs preocupam-se em destacar o acesso aos relatórios financeiros e relatórios de atividades, porém, não há uma preocupação com um sistema de busca avançada, com o desenvolvimento de menus de ajuda ou com a impressão ou download de relatórios financeiros em formato de planilha eletrônica. Por outro lado, nessa dimensão foi constatado que a grande maioria das ONGs possui em seus sites espaço exclusivo (link) para atendimento de doadores, permitindo doações on-line, corroborando com os resultados encontrados por Gandía (2009), que mostraram que mais da metade das ONGs permite que as pessoas façam doações, tornem-se membros ou parceiros através de seus websites.

$\mathrm{Na}$ dimensão Acessibilidade, notou-se que, em média, 44\% das ONGs obtiveram resultados positivos. As diferenças entre $3^{\circ}$ e $1^{\circ}$ quartis são decorrentes principalmente da estrutura do site como existência de um mapa, sistema de busca, hyperlink e link para outros sites. $\mathrm{Na}$ acessibilidade cabe destaque negativo ao atendimento de padrões de acessibilidade para pessoas com deficiência, fator determinante para a inclusão social. Apenas quatro ONGs informam que disponibilizam a tecnologia em Libras. 
Tabela 3: Avaliação da Dimensão Acessibilidade das 100 Melhores ONGs do Brasil, 2018

\begin{tabular}{|c|c|c|}
\hline ade & $\begin{array}{l}\text { Total } \\
\text { Sim }\end{array}$ & 1 Näo \\
\hline $\begin{array}{l}\text { Existe uma área } \\
\text { especifica para relatórios } \\
\text { de atividades e } \\
\text { informações financeiras }\end{array}$ & 65 & 35 \\
\hline $\begin{array}{l}\text { Existem links para outros } \\
\text { sites relacionados }\end{array}$ & 33 & 67 \\
\hline $\begin{array}{l}\text { Um endereço de e-mail } \\
\text { para contato é fornecido }\end{array}$ & 100 & 0 \\
\hline $\begin{array}{l}\text { O conteúdo é } \\
\text { apresentado de forma } \\
\text { estruturada e aninhada e } \\
\text { pode ser acessado } \\
\text { rapidamente e diretamente }\end{array}$ & 91 & 9 \\
\hline $\begin{array}{l}\text { Os títulos são claros, } \\
\text { significativos e a } \\
\text { linguagem usada é } \\
\text { adaptada aos cidadãos }\end{array}$ & 99 & 1 \\
\hline $\begin{array}{l}\text { Há divulgação de } \\
\text { fotografias das atividades } \\
\text { realizadas pela } \\
\text { organização }\end{array}$ & 72 & 28 \\
\hline $\begin{array}{l}\text { Há divulgação de vídeos } \\
\text { das atividades realizadas } \\
\text { pela organização }\end{array}$ & 36 & 64 \\
\hline $\begin{array}{l}\text { Existe um endereço } \\
\text { postal, número de } \\
\text { telefone, etc. para contato }\end{array}$ & 100 & 0 \\
\hline $\begin{array}{l}\text { Existe um sistema de } \\
\text { busca }\end{array}$ & 54 & 46 \\
\hline $\begin{array}{l}\text { Existe um sistema de } \\
\text { busca avançada }\end{array}$ & 1 & 99 \\
\hline $\begin{array}{l}\text { Um mapa do site está } \\
\text { inclúdo }\end{array}$ & 33 & 67 \\
\hline Existe um menu de ajuda & 0 & 100 \\
\hline $\begin{array}{l}\text { Há informação em outros } \\
\text { idiomas }\end{array}$ & 38 & 62 \\
\hline $\begin{array}{l}\text { O download de arquivos } \\
\text { financeiros no formato } \\
\text { de planilha é permitido }\end{array}$ & 0 & 100 \\
\hline $\begin{array}{l}\text { Existe um sistema de } \\
\text { hyperlink que relaciona } \\
\text { diferentes áreas do site }\end{array}$ & 11 & 89 \\
\hline $\begin{array}{l}\text { São utilizados formatos } \\
\text { que permitem a } \\
\text { impressão correta de } \\
\text { informaçőes }\end{array}$ & 0 & 100 \\
\hline $\begin{array}{l}\text { A velocidade de resposta } \\
\text { ao navegar dá efícácia à } \\
\text { consulta }\end{array}$ & 99 & 1 \\
\hline $\begin{array}{l}\text { Existe uma área para } \\
\text { perguntas frequentes }\end{array}$ & 10 & 90 \\
\hline $\begin{array}{l}\text { Estabelece os padrões de } \\
\text { acessibilidade para } \\
\text { pessoas com deficiência }\end{array}$ & 4 & 96 \\
\hline $\begin{array}{l}\text { Indica a data da última } \\
\text { atualização }\end{array}$ & 1 & 99 \\
\hline $\begin{array}{l}\text { Os parceiros têm um } \\
\text { espaço de acesso } \\
\text { exclusivo que lhes } \\
\text { permite realizar } \\
\text { atividades: obter } \\
\text { certificados de doaçöes, } \\
\text { atualizar dados, fazer } \\
\text { contribuiçöes, etc. }\end{array}$ & 88 & 12 \\
\hline $\begin{array}{l}\text { Dimensão Acessibilidade } \\
\text { por Quartil }\end{array}$ & $\operatorname{Sim}$ & Nă \\
\hline $1^{\circ}$ Quartil & $42 \%$ & $58 \%$ \\
\hline $2^{\circ}$ Quartil & $44 \%$ & $56 \%$ \\
\hline $3^{\circ}$ Quartil & $47 \%$ & $53 \%$ \\
\hline
\end{tabular}


Na dimensão Transparência foi avaliada a divulgação de informações relacionadas a ofertas de colaboração para pessoal voluntário, existência de fóruns para críticas e sugestões sobre os trabalhos desenvolvidos, possibilidade de recebimento de atualizações regulares eletronicamente, informações de custos por projetos/atividades, custos com captação de recursos, discussão sobre indicadores contábeis/financeiros, reconhecimento do trabalho voluntário pelo valor justo e seus critérios de apuração, entre outros itens. A Tabela 4 apresenta os resultados detalhados da verificação dessa dimensão.

Nesta dimensão, conforme a Tabela 4, a avaliação dos sites mostra que quase a totalidade das ONGs tem a preocupação em divulgar o trabalho realizado através de diferentes tipos de redes sociais, buscando atingir um público cada vez mais amplo e diversificado. Da mesma forma, preocupam-se em manter contato frequente com seus stakeholders, enviando informações atualizadas através de boletins eletrônicos. 
Tabela 4: Avaliação da Dimensão Transparência das 100 Melhores ONGs do Brasil, 2018

\begin{tabular}{|c|c|c|}
\hline \multirow{2}{*}{ Dimensão Transparência } & \multicolumn{2}{|l|}{ Total } \\
\hline & $\mathrm{Sim}$ & Näo \\
\hline $\begin{array}{l}\text { O site tem um espaço de uso } \\
\text { exclusivo para a } \\
\text { administração da ONG } \\
\text { (Intranet) }\end{array}$ & 12 & 88 \\
\hline $\begin{array}{l}\text { Através do site, o } \\
\text { recrutamento de voluntários é } \\
\text { promovido pela organização }\end{array}$ & 44 & 56 \\
\hline $\begin{array}{l}\text { Ofertas de colaboração são } \\
\text { publicadas para o pessoal } \\
\text { voluntário }\end{array}$ & 31 & 69 \\
\hline $\begin{array}{l}\text { Boletins periódicos de } \\
\text { informação säo publicados } \\
\text { sobre as atividades da } \\
\text { organização }\end{array}$ & 32 & 68 \\
\hline $\begin{array}{l}\text { Existem fóruns abertos } \\
\text { disponiveis para enviar } \\
\text { sugestőes, criticas ou } \\
\text { comentários }\end{array}$ & 0 & 100 \\
\hline $\begin{array}{l}\text { É oferecida aos usuários a } \\
\text { oportuniclade de receber } \\
\text { atualizações regulares } \\
\text { eletronicamente }\end{array}$ & 58 & 42 \\
\hline $\begin{array}{l}\text { Custos por projeto / } \\
\text { programa e atividade }\end{array}$ & 10 & 90 \\
\hline $\begin{array}{l}\text { Informa custos de captação } \\
\text { dos fundos }\end{array}$ & 4 & 96 \\
\hline $\begin{array}{l}\text { Há discussão da relação entre } \\
\text { os custos fixos e os custos } \\
\text { totais da organização }\end{array}$ & 0 & 100 \\
\hline $\begin{array}{l}\text { Há detalhes dos principais } \\
\text { fornecedores e } \\
\text { coorganizadores das } \\
\text { atividades }\end{array}$ & 5 & 95 \\
\hline $\begin{array}{l}\text { Comunica através de redes } \\
\text { sociais (facebook, twitter, } \\
\text { instagram, youtube) }\end{array}$ & 88 & 12 \\
\hline $\begin{array}{l}\text { A DFC é elaborada através } \\
\text { do método direto* }\end{array}$ & 1 & 59 \\
\hline $\begin{array}{l}\text { Doações segmentadas em } \\
\text { institucionais/privadas/pessoas } \\
\text { jurídicas e pessoas fisicas }\end{array}$ & 33 & 67 \\
\hline $\begin{array}{l}\text { Traz análises indicadores } \\
\text { contábeis/financeiros }\end{array}$ & 0 & 100 \\
\hline $\begin{array}{l}\text { O trabalho voluntário é } \\
\text { reconhecido pelo valor justo } \\
\text { da prestação do serviço } \\
\text { como se tivesse ocorrido o } \\
\text { desembolso financeiro* }\end{array}$ & 41 & 30 \\
\hline $\begin{array}{l}\text { São divulgados critérios de } \\
\text { apuraçäo do valor justo do } \\
\text { trabalho voluntário* }\end{array}$ & 23 & 48 \\
\hline $\begin{array}{l}\text { Dimensão Transparência por } \\
\text { Quartil }\end{array}$ & $\operatorname{Sim}$ & Näo \\
\hline $1^{\circ}$ Quartil & $22 \%$ & $78 \%$ \\
\hline $2^{\circ}$ Quartil & $27 \%$ & $73 \%$ \\
\hline $3^{\circ}$ Quartil & $26 \%$ & \\
\hline
\end{tabular}


* Para esses itens, se não havia a documentação adequada para análise, não foi atribuído SIM ou NÃO.

Sobre o reconhecimento do trabalho voluntário pelo valor justo, foi observado que, embora, 41 ONGs informem que procedem desta forma, apenas 23 informam os critérios de apuração. Apesar de autores como Trussel e Parsons (2008) e Portulhak et al. (2015) apontarem que a decisão do doador de efetuar uma contribuição é influenciada pela eficiência na alocação de recursos, pela estabilidade financeira da organização e disponiblidade de informações, nenhuma ONG divulga discussões gerenciais sobre os seus indicadores contábeis e financeiros e apenas quatro informam sobre seus custos com captação de recursos.

Em contraste, Gordon et al. (2010) apontaram em seu estudo que 33\% das ONGs apresentavam algum tipo de discussão gerencial sobre o desempenho financeiro da organização. Embora seja preciso considerar que há evidências diretas de que os gestores de ONGs sofrem pressão para relatar índices favoráveis e em função disso, estão dispostos a gerenciar os números (Parsons, Pryor, \& Roberts, 2017). A manipulação de dados contábeis, contudo, é apontada como menos disfuncional que decisões operacionais como despesas inadequadas com salários e com captação de recursos. $O$ pagamento de baixos salários e a contratação tardia de ferramentas de inovação tecnológica, por exemplo, podem afetar a retenção e contração de profissionais qualificados e o monitoramento da efetividade das ações institucionais para o público-alvo (Parsons et al., 2017).

Em média, na dimensão Transparência o resultado foi o atendimento dos critérios por apenas $25 \%$ das ONGs. Apenas nessa dimensão as ONGs do $2^{\circ}$ quartil apresentaram resultados melhores que as do $3^{\circ}$ quartil. Tal fato deve-se principalmente a um maior detalhamento das doações recebidas e ao recrutamento e oferta de colaboração para pessoal voluntário através dos sites. O baixo nível de transparência corrobora com os achados de Oliveira e Coelho (2017), que afirmam que a transparência é pouco praticada pelas ONGs e que esse fato pode ter relação com a decisão de doação estar mais vinculada à responsabilidade social individual do que à análise da presença e qualidade da prestação de contas da organização.

Apesar de Gordon et al. (2010) destacarem que o método indireto de elaboração do fluxo de caixa tem se mostrado de difícil entendimento para usuários, evidenciaram em seu estudo que apenas três ONGs utilizavam o método direto, enquanto neste estudo apenas uma ONG informou que prepara a demonstração por tal método.

Na dimensão Divulgação Total foi avaliado se a divulgação voluntária da ONG vai além de fatos favoráveis, sob a ótica da Teoria da Divulgação (Verrecchia, 2001). Os resultados da análise são apresentados na Tabela 5.

Tabela 5: Avaliação da Dimensão Divulgação Total das 100 Melhores ONGs do Brasil, 2018

\begin{tabular}{|c|c|c|}
\hline Dimen: & Total & \\
\hline Total & $\operatorname{Sim}$ & Não \\
\hline $\begin{array}{l}\text { Há detalhamento de } \\
\text { politicas relacionadas ao } \\
\text { doador }\end{array}$ & 3 & 97 \\
\hline $\begin{array}{l}\text { Lista os principais } \\
\text { doadores }\end{array}$ & 23 & 77 \\
\hline $\begin{array}{l}\text { Relata potenciais } \\
\text { conflitos de interesse }\end{array}$ & 6 & 94 \\
\hline $\begin{array}{l}\text { Informa sobre parcerias } \\
\text { com financiadores } \\
\text { públicos/privados, } \\
\text { associações ou empresas }\end{array}$ & 18 & 82 \\
\hline $\begin{array}{l}\text { Dimensão Divulgação } \\
\text { Total por Quartil }\end{array}$ & $\operatorname{Sim}$ & Näo \\
\hline $1^{\circ}$ Quartil & $7 \%$ & $93 \%$ \\
\hline $2^{\circ}$ Quartil & $14 \%$ & $87 \%$ \\
\hline $3^{\circ}$ Quartil & $16 \%$ & $84 \%$ \\
\hline
\end{tabular}


Nessa dimensão, as ONGs classificadas no $1^{\circ}$ quartil apresentaram os piores resultados. Apenas seis ONGs declararam, minimamente, algum conflito de interesse, embora tais conflitos possam não existir para as demais. Poucas ONGs disponibilizam para consulta os instrumentos jurídicos que tratam de suas parcerias, o que facilitaria a avaliação da existência de outros possíveis conflitos de interesses, sendo que a disponibilização para consulta de convênios, contratos e instrumentos congêneres que tratam das parcerias com entes públicos e (ou) privados é o item com maior discrepância entre o $1^{\circ}$ e $3^{\circ}$ quartis.

Quando não há divulgação de transações com partes relacionadas, os usuários entendem que não houve esse tipo de transação, mas é preciso evitar o fator surpresa (Gordon et al., 2010). Esses autores apontam que a aderência aos desejos dos doadores é uma obrigação ética da ONGs e a Divulgação Total não deve ser apenas na forma de cumprimento de um checklist, conforme evidenciaram ser a prática das ONGs por eles estudadas, mas sim, deve ser acompanhada de uma explicação narrativa e compor o relatório de atividades.

A dimensão que mostrou melhores resultados foi a dimensão Relevância, conforme indica a Tabela 6. Em média, 71\% das ONGs estudadas divulgaram de forma clara e inequívoca seu campo e forma de atuação e seu impacto social, deixando seus objetivos claros e precisos. A missão e visão são claramente definidas pela maioria das ONGs, contudo, embora os valores sejam enunciados, são poucas as ONGs que os interpretam de forma mais aprofundada. Tais resultados corroboram com os achados de Gandía (2009), que destacou que muitas ONGs não utilizam a web para atender objetivos estratégicos, mas para passar uma imagem de modernidade e inovação, muitas vezes, imitando os sites de outras ONGs. 
Tabela 6: Avaliação da Dimensão Relevância das 100 Melhores ONGs do Brasil, 2018

\begin{tabular}{|c|c|c|}
\hline Dimensão Relevância & $\begin{array}{l}\text { Total } \\
\text { Sim }\end{array}$ & 1 Näo \\
\hline $\begin{array}{l}\text { Informa claramente } \\
\text { sobre seu campo de } \\
\text { atividade }\end{array}$ & 100 & 0 \\
\hline $\begin{array}{l}\text { Indica inequivocamente } \\
\text { quem são os } \\
\text { beneficiários das suas } \\
\text { operações }\end{array}$ & 100 & 0 \\
\hline $\begin{array}{l}\text { A missão da organização } \\
\text { está claramente definida }\end{array}$ & 92 & 8 \\
\hline $\begin{array}{l}\text { A visão da organização é } \\
\text { claramente definida }\end{array}$ & 77 & 23 \\
\hline $\begin{array}{l}\text { Os valores são } \\
\text { enunciados e a } \\
\text { interpretação que a } \\
\text { organização faz deles é } \\
\text { definida }\end{array}$ & 23 & 77 \\
\hline $\begin{array}{l}\text { Informações sobre os } \\
\text { interesses representados, } \\
\text { sejam eles religiosos, } \\
\text { politicos, trabalhistas ou } \\
\text { corporativos }\end{array}$ & 100 & 0 \\
\hline $\begin{array}{l}\text { Os objetivos da } \\
\text { organização são claros, } \\
\text { precisos e capazes de } \\
\text { serem avaliados }\end{array}$ & 99 & 1 \\
\hline $\begin{array}{l}\text { Informa a relação entre } \\
\text { os programas/projetos } \\
\text { desenvolvidos e as } \\
\text { conquistas alcançadas } \\
\text { e/ou esperadas (Esforços } \\
\text { presentes, Plano de Ação } \\
\text { exercício vigente) }\end{array}$ & 15 & 85 \\
\hline $\begin{array}{l}\text { Informa a relação entre } \\
\text { os programas/projetos }\end{array}$ & & \\
\hline $\begin{array}{l}\text { desenvolvidos e as } \\
\text { conquistas alcançadas } \\
\text { e/ou esperadas (Es forços } \\
\text { Passados) }\end{array}$ & 96 & 4 \\
\hline $\begin{array}{l}\text { Informa a relação entre } \\
\text { os programas/projetos } \\
\text { desenvolvidos e as }\end{array}$ & & \\
\hline $\begin{array}{l}\text { conquistas alcançadas } \\
\text { e/ou esperadas (Esforços }\end{array}$ & 8 & 92 \\
\hline $\begin{array}{l}\text { Futuros, Plano de Ação } \\
\text { próximos exercícios) }\end{array}$ & & \\
\hline $\begin{array}{l}\text { Dimensão Relevância por } \\
\text { Quartil }\end{array}$ & Sim & Não \\
\hline $1^{\circ}$ Quartil & $67 \%$ & $33 \%$ \\
\hline $2^{\circ}$ Quartil & $71 \%$ & $29 \%$ \\
\hline $3^{\circ}$ Quartil & $76 \%$ & $24 \%$ \\
\hline
\end{tabular}

Também como evidenciado na Tabela 6, há preocupação da maioria das ONGs em relatar seus esforços passados e conquistas alcançadas nos relatórios e informações disponibilizadas on-line, porém, destas, apenas uma pequena proporção preocupa-se em disponibilizar um plano de ação para o exercício atual ou algum 
tipo de planejamento estratégico para exercícios futuros, com discussão de tendências. Ao contrário, Gordon et al. (2010) evidenciaram que quase $100 \%$ das ONGs descreviam em forma de narrativa seus esforços para o ano corrente.

De forma geral, os resultados positivos médios das cinco dimensões são: $33 \%$ para o $1^{\circ}$ quartil; 39\% para o $2^{\circ}$ quartil; e $41 \%$ para o $3^{\circ}$ quartil, corroborando com as afirmações de Salamon (1998) de que as ONGs, conforme se desenvolvem, ganham volume e complexidade, precisando passar a atender exigências típicas de qualquer instituição mais burocrática ou empresarial, principalmente questões relacionadas à accountability. Sendo avaliadas as dimensões de forma isolada, a hipótese indicada para o objetivo específico da pesquisa é acatada para todas as dimensões, excetuando-se à dimensão "Transparência", em que as organizações apresentadas no $2^{\circ}$ quartil apresentaram resultado superior às organizações do $3^{\circ}$ quartil.

Em suma, os resultados e análises apresentados evidenciam que as organizações pesquisadas utilizam seus sites mais intensamente para fornecer informações gerais e com o intuito de promover suas ações do que para divulgar outras informações que possam ser consideradas relevantes para prestação de contas aos seus diferentes parceiros. Tal conclusão vai ao encontro das conclusões de Gandía (2009), que indicou a proeminência da dimensão de relevância na divulgação de informações.

Esse achado implica na recomendação, alinhado às afirmações de Gordon et al. (2010), de que também seria importante para estas ONGs a ampliação de seus esforços de divulgação sobre ações para o fortalecimento do controle interno e sobre medidas tomadas para aumentar a percepção de confiabilidade de sua contabilidade e de seus relatórios gerenciais. Esta atitude pode resultar em aumento da confiança dos doadores e da opinião pública, reduzindo os riscos de perda de espaço de atuação em favor de organizações empresariais (Salamon \& Newhouse, 2019).

Já a respeito da hipótese na qual se esperava que ONGs com maior porte apresentassem maior accountability, os resultados indicaram que esta pode ser aceita de forma geral e para as dimensóes "Completude", "Acessibilidade", "Divulgação Total" e "Relevância", estando de acordo com o indicado por Salamon (1998) e em consonância com a hipótese de Lang e Lundholm (1993), calcada na Teoria da Divulgação, a respeito da restrição dos custos de preparação, enquanto não foi aceita para a dimensão "Transparência”. Para a literatura sobre o tema, entende-se que este é um achado singular, que pode que ser explicado pela disposição mais específica de gestores para o atendimento de cláusulas contratuais pontuais vinculadas a doações privadas para programas específicos ou a financiamentos com recursos públicos, e não orientada à dependência da receita total de doações, vinculada a um público mais amplo (Parsons et al., 2017).

\section{CONCLUSÕES}

Buscando contribuir para que organizações sem fins lucrativos tenham subsídios para melhorar suas práticas de prestação de contas e, consequentemente, possam aumentar a confiança de seus stakeholders e alcançar sustentabilidade financeira em um ambiente de crescente competição por recursos, o objetivo deste estudo foi identificar os elementos presentes na prestação de contas voluntária das 100 melhores ONGs do Brasil, considerando as melhores práticas dentre cinco dimensões de eficácia: completude, acessibilidade, transparência, divulgação total e relevância.

Os resultados, a despeito de estas instituições estarem listadas no rol de melhores ONGs do Brasil, corroboraram com o estudo junto a ONGs espanholas de Gandía (2009), indicando um baixo nível de divulgação voluntária na web por estas organizações, o que está de acordo com o pressuposto oriundo do objetivo geral da investigação. Há, portanto, oportunidades para que essas ONGs possam melhorar o conteúdo informacional disponibilizado de forma pública, tornando seus sites mais interativos e deliberativos.

Esses resultados revelam que as ONGs investigadas demonstram maior preocupação em mostrar sua relevância e impacto social através de enunciados de sua missão e visão, da expressividade de seus relatórios 
de atividades e divulgação de imagens, corroborando com a ideia de que a necessidade de legitimidade externa e pressões institucionais provavelmente acabam influenciando mais as dimensões de eficácia do que as necessidades internas de melhorias no funcionamento e na eficiência operacional (Lee \& Nowell, 2015; Parsons et al., 2017).

Ademais, pelo o que foi identificado neste e em estudos anteriores, pode haver uma tendência das ONGs em relatar o mesmo que os concorrentes mais próximos (Gandía, 2009; Gordon et al., 2010). As variações entre organizações que têm a mesma área de atuação podem estar relacionadas à crença de alguns gestores que certas informações não seriam utilizadas pelos doadores, enquanto outros gestores acreditam que a divulgação sinaliza um alto grau de responsabilidade, embora a literatura recomende que toda informação esteja disponível.

Como limitações do estudo, é preciso ressaltar a dificuldade na obtenção e interpretação de informações relacionadas a dados contábeis, número de funcionários, número de voluntários, segmentação das doações em pessoas físicas e jurídicas e informações precisas sobre fontes de recursos. Isso se deve à ausência de informações nos sites ou dificuldade de comparabilidade, dadas as diferentes formas de divulgação. Assim, não foi possível analisar a eventual relação desses fatores com os resultados obtidos. Complementarmente, seria preciso comparar os achados aqui relatados com resultados de estudos que venham a contemplar um rol de organizações não agraciadas com esse prêmio, que ocasionalmente podem apresentar resultados ainda menos expressivos.

Entende-se que este estudo contribui do ponto de vista teórico ao identificar e discutir proposições e práticas de prestação de contas voluntária por organizações do terceiro setor, com base em ONGs consideradas como referência, ressaltando a importância dada por estas para a dimensão "Relevância", bem como ao identificar que, para a maioria das dimensões analisadas, há uma relação entre o porte da ONG e o nível de divulgação, em linha com o indicado em desenvolvimentos já realizados na Teoria da Divulgação.

Do ponto de vista prático e social, o estudo colabora com as organizações dessa natureza que almejam tornar sua prestação de contas, especialmente por meio de suas páginas na internet, uma ferramenta para estreitar relações com diferentes stakeholders, atrair novos parceiros e fidelizar os atuais colaboradores. Ao considerar as prescriçóes presentes na literatura e as práticas das ONGs consideradas como referência por conta de seu desempenho - nas quais também se observam oportunidades de melhoria -, estas teriam à disposição uma relação de elementos a serem observados por seus gestores para uma prestação de contas voluntária adequada, algo entendido como primordial à sua sustentabilidade.

Como proposta para estudos futuros, caberia a análise estatística do impacto das dimensões aqui avaliadas na obtenção de recursos de doadores individuais, doadores institucionais e órgãos públicos. Ademais, embora as ONGs estudadas tenham mostrado um baixo nível de divulgação em seus websites, por comporem o rol das 100 melhores ONGs do Brasil em 2018, tendem a ter práticas de prestação de contas que podem servir de referência em um estudo comparativo com outras ONGs, que por sua vez podem apresentar práticas de divulgação on-line ainda mais limitadas.

\section{REFERÊNCIAS}

Alves, M. A. (2002, setembro). Terceiro Setor: as origens do conceito. Anais do XXVI Encontro dos Programas de Pós-Graduação em Administração, Salvador, BA, Brasil, p. 26.

Banding, M., Mayangsari, S. (2017). The impact of financial and non-financial information disclosure to donation decision in nonprofit organization by individual donor. Research Journal of Finance and Accounting, 8(16), 9-19.

Costa, M. M. da (2017). Análise de colaborações entre governo e ONGs e da densidade de ONGs no Brasil. Revista de Administração Pública, 51(3), 330-347. 
Cruz, C. V. O. A. (2010). A relevância da informação contábil para os investidores sociais privados de entidades do Terceiro Setor no Brasil: uma investigação empírica (Tese de doutorado). Universidade de São Paulo, São Paulo SP, Brasil. Recuperado de http://www.teses.usp.br/teses/disponiveis/12/12136/tde-24062010-104557/pt-br. php

Ebrahim, A. A. (2003). Accountability in practice: mechanisms for NGOs. World Development, 31(5), 813-829.

Falconer, A. P. (1999). A promessa do terceiro setor: um estudo sobre a construção do papel das organizações sem fins lucrativos e do seu campo de gestão (Dissertação de mestrado). Universidade de São Paulo, São Paulo, SP, Brasil. Recuperado de http://www.lasociedadcivil.org/wp-content/uploads/2014/11/andres_falconer.pdf

Fischer, R. M. (2004). Gestão de pessoas nas organizações do terceiro setor. In R. Voltolini (Org.), Terceiro setor: planejamento e gestão (pp. 77-102). São Paulo: Senac.

Gandía, J. L. (2009). Internet disclosure by nonprofit organizations: empirical evidence of nongovernmental organizations for development in Spain. Nonprofit and Voluntary Sector Quarterly, 40(1), 57-78.

Gordon, T. P., Khumawala, S. B., Kraut, M., Neely, D. G. (2010). Five dimensions of effectiveness for nonprofit annual reports. Nonprofit Management \& Leadership, 21(2), 209-228.

Gordon, T. P., Khumawala, S. B. (1999). The demand for not-for-profit financial statements: a model of individual giving. Journal of Accounting Literature, 18, 31-56.

Guimarães, L., Craveiro, P. (2018). Guia 100 melhores ONGs 2018. São Paulo: Instituto Doar. Recuperado de http ://www.institutodoar.org/guiamelhores/

Instituto Brasileiro de Geografia e Estatística. (2019). As fundações privadas e associações sem fins lucrativos no Brasil: 2016. Rio de Janeiro: IBGE. Recuperado de https://biblioteca.ibge.gov.br/visualizacao/livros/liv101647.pdf

Krlev, G., Lund, A. B. (2020). Social innovation ignored: framing nonprofit activities in European news media. Voluntas: International Journal of Voluntary and Nonprofit Organizations, 31, 949-965.

Landim, L. (1993). A invenção das ONGs: do Serviço invisível à profissão impossível. (Tese de doutorado). Universidade do Rio de Janeiro, Rio de Janeiro, RJ, Brasil.

Lang, M., Lundholm, R. (1993). Cross-sectional determinants of analyst ratings of corporate disclosures. Journal of Accounting Research, 31(2), 246-271.

Langford, E. (2006). Quartiles in elementary statistics. Journal of Statistics Education, 14(3), 1-20.

Lee, C., Nowell, B. (2015). A framework for assessing the performance of nonprofit organizations. American Journal of Evaluation, 36(3), 299-319.

Lei n. 13.204, de 14 de dezembro de 2015. (2015). Altera a Lei n. 13.019, de 31 de julho de 2014. Recuperado de htt p://www.planalto.gov.br/ccivil_03/_Ato2015-2018/2015/Lei/L13204.htm

Lima, M. B. (2016). O terceiro setor e a prestação de contas por serviços públicos executados a partir do Decreto 7.592/2011 (Dissertação de mestrado). Universidade Federal de Brasília, Brasília, DF, Brasil.

Mañas, A. V., Medeiros, E. E. (2012). Terceiro setor: um estudo sobre a sua importância no processo de desenvolvimento sócio-econômico. Perspectivas em Gestão \& Conhecimento, 2(2), 15-29.

Marco regulatório das organizações da sociedade civil: a construção da agenda no governo federal - 2011 a 2014. (2015). Elaborado pela Secretaria-Geral da Presidência da República. Brasília, DF: Governo Federal. Recuperado de http://plataformamaisbrasil.gov.br/images/docs/MROSC/Publicacoes_SG_PR/04.12.15_MROSC_Arqu ivoCompleto_Capa_Miolo.pdf

Mário, P. do C., Paula, C. L. S. de, Alves, A. D. de F., Jupetibe, F. K. N. (2013). Evidenciação das fundações privadas de Belo Horizonte: prestação de contas e qualidade da informação. Pensar Contábil, 15(56), 29-41.

McKeever, B. S. (2018). The nonprofit sector in brief 2018: public charities, giving, and volunteering. National Center for Charitable Statistics. Recuperado de https://nccs.urban.org/publication/nonprofit-sector-brief-2018\#all-n onprofit-organizations

Oliveira, W. E. S., Coelho, C. U. F. (2017). Transparência das informações e seu impacto no valor econômico: um estudo em organizaçóes do Terceiro Setor. Pensar Contábil, 19(70), 44-51. 
Parsons, L. M. (2007). The impact of financial information and voluntary disclosures on contributions to not-forprofit organizations. Behavioral Research in Accounting, 19(1), 179-196.

Parsons, L. M., Pryor, C., Roberts, A. A. (2017). Pressure to manage ratios and willingness to do so: evidence from nonprofit managers. Nonprofit and Voluntary Sector Quarterly, 46(4), 705-724.

Portulhak, H., Delay, A. J., Pacheco, V. (2015). Prestação de contas por entidades do Terceiro Setor e seus impactos na obtenção de recursos: um olhar sobre o comportamento dos doadores individuais. Pensar Contábil, 17(64), $39-47$.

Salamon, L. (1998). A emergência do terceiro setor - uma revolução associativa global. Revista de Administração, 33(1), 5-11.

Salamon, L. M., Newhouse C. L. (2019). The 2019 Nonprofit employment report. Nonprofit Economic Data Bulletin, 47. Baltimore: The Johns Hopkins Center for Civil Society Studies. Recuperado de http://ccss.jhu.edu/wp-con tent/uploads/downloads/2019/01/2019-NP-Employment-Report_FINAL_1.8.2019.pdf

Salamon, L. M., Sokolowski, S. W., List, R. (2003). Global civil society: An overview. Baltimore: The Johns Hopkins Center for Civil Society Studies. Recuperado de http://ccss.jhu.edu/wp-content/uploads/downloads/2011/09 /Book_GCSOverview_2003.pdf

Sampieri, R. H., Collado, C. F., Lucio, P. B. (2006). Metodologia de pesquisa (3a ed.). São Paulo: Mc-Graw-Hill.

Trussel, J. M., Parsons, L. M. (2008). Financial reporting factors affecting donations to charitable organizations. Advances in Accounting, 23, 263-285.

Verrecchia, R. E. (2001). Essays on disclosure. Journal of Accounting and Economics, 32(1-3), 97-180. 